\title{
RESEÑA DE LIBROS
}

Luis EMilio HenaO. Tehuacán. Campesinado e irrigación. 1980, Ed. Edicol, México. 284 páginas.

El libro que comentamos es el resultado de un trabajo final para la Maestría en Antropología Social de la Universidad Iberoamericana y se basa en una investigación realizada en el municipio deSan Juan Ajalpan, en el Vallede Tehuacán, Estado de Puebla.

La investigación se propuso efectuar un estudio del campesinado "desde el punto de vista de sus formas de organización y específicamente a través de la organización social para el manejo de los recursos hidráulicos" (p. 14). Para ello se realizó un análisis de la com unidad campesina en un doble proceso: "el con" trol de los recursos ecológicos por los grupos campesinos y el control de los grupos campesinos y de los recursos ecológicos por el sistema dominante" (p.15).

Nuestros comentarios se referirán solamente a un aspecto, recortadoen una forma que no pretende recuperar los a portes centrales del autor. Dicho aspecto tiene que ver con el estudio de una pequeña región y a las relaciones sociales y técnicas que dentro de ellas establecen los grupos sociales en el desarrollo de sus estrategias de sobrevivencia y reproducción.

En forma sumaria podemos decir que Henaoestudia un objeto que puededefinirse de la siguiente forma: como base material un territorio definido: el Valle de Tehuacán; dentro de esa base los sectores sociales que utilizan dicho territorio en distintas estrategias productivas y sociales; las manifestaciones sociales que se establecen en el uso de dicho territorio: especialmente en relación al uso de la tierra y el agua como los recursos naturales fundamentales para la reproducción social; y por último, la incidencia, en esos actores y esas relaciones del peso de la sociedad nacional en diversas coyunturas históricas.

Repetimos que el trabajo que analizamos contiene muchos más elementos y que, una lectura antropológica le haria justicia en relación a ellos. De todas formas creemos que con base en el recorte que efectuamos es posible utilizar este trabajo como fuente de conocimiento de una realidad muy pobremente estudiada: "realidades sociales regionales".

El libro de Henao ilustra una de esas realidades ya que éstas constituyen, según nuestro entender una unidad compuesta por un ámbito territorial determinado y un sistema social de producción de una o más fracciones sociales basado en dicho ámbito. 
La orientación del trabajo de Henao conduce su estudio a un planteamiento que constituye sus proposiciones teniendo en cuenta la vinculación doble de cada una de las fracciones sociales regionales: con los recursos ecológicos(agua y tierra) y con las demás fracciones sociales. Deesta forma dichosgrupos se definen con una doble referencia: el ámbito territorial y al sistema de relaciones sociales que se constituye en él.

El libro se arma en gran medida en relación al relato de las relaciones entre la comunidad campesina (de baseindígena) y su organización social para el aprovechamiento de la tierra y el agua con las haciendas y el gobierno colonial, en un primer momento; incorporado luego el papel de los grupos mestizos y, por último, las relaciones que se mantienen, luego de la Revolución y con la aplicación de la Reforma Agraria, al emerger una cantidad diferenciada de actores y formas organizativas (ejidos, comunidades, pequeños propietarios, sociedades de aguas). Comoúltimo aspecto seanalizan, másen detalle, las "sociedades explotadoras y distribuidoras de aguas".

Dent ro de ese conjunto muy rico en aspectos y detalles, realizaremos solamente una reflexión que vincule los aspectos referidos a la dimensión regional del objeto estudiado por Henao.

En primer lugar se percibe claramente cómo el Valle de Tehuacán constituye una unidad ecológica en la reproducción del campesinado como grupo social. No significa esto que el Valle sea únicamente la unidad ecológica de la reproducción de ese grupo social, sino que - dadas las características del estudio que comentamos-, se ha recortado, o mejor, enfocado predominantemente a dicho grupo. Es cierto también que el campesinado ha interactuado con otros sectores sociales quienes, a su vez, también han utilizado el Valle como unidad ecológica de reproducción, aunque pudieran excederla. La mencionada interacción, normalmente contradictoria, ha sido una de las condicionantes sociales de la reproducción del campesinado.

Resulta interesante la vinculación del desarrollo de las formas organizativas de los campesinos con el control del uso del agua. Sepudiera tomar esta relación (fracción social-recurso natural) para plantear algunos elementos sobrela existencia del ámbito regional y la forma de reproducción social que lo caracteriza.

Si pensamos que el campesino como tal encuentra como condición para su reproducción (dadas las características del ámbito regional en que habita) la posibilidad del uso del agua, dado que en un principio cuenta con tierras suficientes en cantidad pero que necesitan riego, podemos entender quela relación entre los campesinos y el agua se vuelve funda mental para las estrategias deproducción y de reproducción social de ese sector.

La relación campesinado-agua supone un sistema social de relaciones, por una parte con los demás sectores regionales, y, por la otra, con el sistema nacional, tanto económico como político.

De acuerdo a lo que dice Henao, pareciera que las cambiantes relaciones entre los campesinos del Valle y el gobierno nacional constituirian, históricamente, el contexto funda mental dentro del cual se dio la relación con el aguay, consecuentemente, la reproducción social de los campesinos.

La vinculación con el gobierno nacional se da, de acuerdo al autor, en cinco momentos históricos diferentes, aunque con una constante en "las reformas de 
la propiedad de la tierra y del agua decretadas por el gobierno nacional con la contracción y subordinación de la comunidad campesina y la expansión de la apropiación privada de los recursos con el fin de propiciar el desarrollo de la economia mercantil" (p.255).

En primer momento, al comenzar el siglo XVII, el gobierno colonial crea las comunidades indigenas, las organiza corporativamente y dependientes política y económicamente del mismo gobierno. La legislación agraria libera considerable cantidad de tierras y agua que se ponen a disposición de los españoles que formarán las haciendas del Valle. El gobierno interno es utilizado para imponer las políticas coloniales a los indígenas y para asegurar el pago del tributo. Comienza, además a destruirse el sistema prehispánico de riego, en lofísico yen lo social. En segundo momento, en el siglo XVIII, se remodelan las comunidades indígenas, imponiéndoles patrones de organización social ya obsoletos, incrementando las características culturales tradicionales y permitiendo la extracción forzada de trabajo para las haciendas, de dinero para la Corona y de ma no de obragratuita para las obras públicas. Se subordina la producción indigena frente a las haciendas, por la extracción de obra y la apropiación del agua por parte de éstas. En suma, la "tradicionalización de la organización social y la contracción del sistema productivo indígena son medidas que permiten la subordinación estructural al sistema nacional y a la agricultura comercial de las haciendas" (p. 258). El tercer momento, durante las reformas liberales, se caracteriza por el intento de quitar el control del agua y la tierra delas manosdelas comunidades, lanzando fuerza de trabajo barata para las haciendas. Se fortalecen las grandes haciendas. En el cuarto momento, luego delas luchas revolucionarias, las leyes de reforma agraria se aplican por medio de la burguesía rurallocal y se manipula a las organizaciones para la obtención del control del agua para dar paso a una organización oficial. Además, "mientras la burguesía local y las haciendas amplian su campo de acción en lo económico y en lo político hacia niveles regionales y nacionales, el campesinado es concentradoen organizaciones de carácter localista con intereses limitados y sometidos al caciquismo local" (p. 259). El quinto momento aún abierto, se habría iniciado hacia 1950 y terminaría con el control del gobierno nacional sobre el agua del Valle.

Como sugerimos antes, las relaciones entre los campesinos y el agua, fundamentales para su reproducción social, se encuentran mediadas por la presencia regional de los efectos de las acciones del estado nacional, aun desde la colonia. Esto indica una situación de heteronomía social y política del campesinado que le impide controlar el medio ambiente de acuerdo a sus necesidades e in tereses. Igualmente implica la necesidad de ir adecuando sus organizaciones para poder cubrir sus intereses en las cambiantes situaciones que le van definiendo sus interlocutores: las haciendas, loscomerciantes y el gobierno nacional predominantemente.

Es interesante observar cómo se da la presencia local del gobierno nacional. Según Henao es una presencia indirecta, mediada por un "sinnúmero de personas e instituciones que intermedian entre el campesinado y la sociedad nacional: el grupo del cáciquismo local, los políticos, las organizaciones políticas y sindicales regionáles, los comerciantes, los lideres acaparadores, los que poseen conocimiento jurídico, los líderes de las organizaciones, los que propor- 
cionan créditos y losque asesoran dealguna forma a losgrupos campesinos" (p. 263). Así se entiende que el caciquismo es, más que un fenómeno de personas, "un estrato burgués que encuentra en ella (la persona del cacique) su expresión y posibilidad de actuación"'(p. 264). Es este estrato social el que asume la capacidad de decisión en la distribución de las aguas y el reparto de las tierras en el ejercicio del poder a nivel local y regional y cuenta con mecanismos de dominación y subordinación contra las organizaciones campesinas.

Es interesante esta indicación de la existencia de un sistema de mediación entre lo local y lo nacional. Sistema este que siendo local puede trascender sus fronteras y ofrecer al sistema nacional el control de la realidad regional. Se constituye así una articulación regional en la dominación nacional por medio de ese grupo que viene a fungir como el encargado regional de los intereses del "centro". Pero lo que si es discutible en el texto es la inclusión de la burguesía dentro de ese estrato mediador. Esta inclusión nos produce dos tipos de dudas: la primera se refiere a la realidad de esa así llamada burguesía. No nos queda en claro que efectivamentese trate de una fracción social que pueda con toda legitimidad llevar ese nombre, sin agregarle algún aditamento que de alguna forma relativice su definición social. Este elemento que se refiere a su definición estructural, puede ser ampliado tomando una observación que realiza el propio Henao: "así como sorprende ver la proliferación de organizaciones de la burguesía agraria" (p. 265). No convence el argumento del autor de que la organización "es un elemento propio de la clase marginada" si es que se quiere afirmar que es exclusivo de ella (de otra forma se estaría realizando una afirmación sumamente obvia). Más bien debería referirse a la inexistencia de verdadera burguesía local. Esto nos conduce al segundo tipo de dudas. La existencia de fracciones sociales propietarias no significaría realmente la existencia de burguesía en la medida en que sería más bien la existencia de fracciones sociales no autónomas, caracterizadas por cumplir una función mediadora y, consecuentemente, no sólo a nivel político sino también económico, constituir un canal de transmisión de los excedentes para el centro. Esta hipótesis que formulamos, debemos reconocer, no encuentra asidero en las proposiciones que ofrece $\mathrm{He}$ nao, pero tal vez puede orientar la investigación en un nuevo sentido.

Tal como entendemos la mencionada mediación supone la función de incorporar la región, esto es al conjunto de sistemas productivos regionales y a las fracciones sociales basadas en ellos, a la nación. Dicha incorporación supone, igualmente, la limitación del desarrollo de la acumulación local de los excedentes productivos, por su transferencia, y la limitación de la capacidad de los grupos locales para controlar su medio ambiente y el sentido de las relaciones sociales que en él se desenvuelven, esto es una limitación del poder local autónomo.

Atendiendo al sistema social regional, de acuerdo a lo propuesto por Henao, se observa una constante contradicción entre los principales actores por el control de la tierra, el agua y la mano de obra. En esas luchas los campesinos constituyen -dado el análisis que comentamos-el sector social centralque se vincula diferencialmente con los demás: haciendas, mestizos, burocracias gubernamentales.

En este sistema de relaciones la imagen que el libro da del campesinado es el 
de una clase social a la defensiva, que va siendo desplazada del lugar central que tuvo en la región y que, al ser articulada al desarrollo de las formas mercantiles, desarrolla una estrategia de múltiples formas para lograr sobrevivir como tal, aunque esa misma estrategia signifique, necesariamente, cierta pérdida de identidad social. Así, "la ampliación de los recursos ecológicos, la combinación de las fuerzas productivas y la elasticidad de las relaciones sociales, ha permitido que una misma persona se esté moviendo casi simultáneamente en diversas áreas de la producción. El agricultor es también artesano de la canasta. El tejero también es agricultor y accionista de una sociedad deaguas y puedeser pequeño comerciante. El pequeño agricultor puede ser también matancero, pequeño comerciante, accionista de aguas y fletar mercancías... En otras palabras, la subsistencia de la unidad fa miliar nodependeexclusivamente de un factor, como podría ser el trabajo asalariado" (p. 178).

Esa necesidad de diversificación es una consecuencia de no lograr una plena reproducción como campesinos y estoes, a su vez, una consecuencia de pérdida del control sobre los recursos naturales, especialmente el agua. En esto la intervención del gobierno nacional aparece como la condición necesaria externa para dicho desplazamiento social del campesinado. Como dice Henao: "se trata de una intervención clínica del gobierno nacional por la cualel ca mpesinado es afectado en su desarrollo económico, pero siendo incorporado en su posición subordinada y haciendo tradicionales sus formas de organización social, todo lo cual posibilita cierto desarrollo del sistema económico nacional" ( $p$. 261).

Para terminar nuestro comentario mencionaremos el análisis de las contradicciones que surgen de la vinculación del cam pesinado con el agua y su control: contradicción entre la cantidad de agua disponible y el crecimiento dela población que impide la formación de una agricultura intensiva y produce la emergencia de distintas formas de obtención del agua que dan lugar a nuevas formas sociales. Contradicciones entre los estratos sociales campesinos que sediferencian en el sistema distributivo de agua y, consecuentemente, en el sistema productivo. Contradicción entre la forma interna de gobierno y la forma impuesta desde el exterior. Contradicción entre la religiosidad popular y la religiosidad oficial. Contradicción entre el sistema productivo de la comunidad y el de las haciendas y de los propietarios privados: conflictos porel predominio de un sistema productivo y a expensas del otro, uno desarrollándose hacia la agricultura comercial y el otro manteniéndose en la producción para la subsistencia.

Pedro Pírez 